\title{
Lack of correlation between blood group and HER-2 status in adenocarcinomas of the upper gastrointestinal tract
}

\author{
MICHAEL HEJNA $^{1,7}$, PETER BIRNER ${ }^{2,7}$, MATTHIAS PREUSSER ${ }^{1,7}$, CHRISTIANE M. R. THALLINGER $^{1}$, \\ NINA WOREL ${ }^{3}$, REZAASARI ${ }^{4,7}$, WERNER DOLAK ${ }^{5,7}$, RAINER SCHMID ${ }^{6,7}$, \\ SEBASTIAN F. SCHOPPMANN ${ }^{4,7}$ and MARKUS RADERER ${ }^{1}$ \\ Departments of ${ }^{1}$ Internal Medicine I, ${ }^{2}$ Pathology, ${ }^{3}$ Blood Group Serology/Transfusion Medicine, \\ ${ }^{4}$ Surgery, ${ }^{5}$ Internal Medicine III, ${ }^{6}$ Radiotherapy; ${ }^{7}$ Comprehensive Cancer Center, \\ Medical University of Vienna, A-1090 Vienna, Austria
}

Received May 23, 2013; Accepted August 15, 2013

DOI: $10.3892 /$ mco.2013.181

\begin{abstract}
The assessment of the human epidermal growth factor receptor-2 (HER-2) status has become a routine diagnostic procedure for patients with advanced-stage gastroesophageal adenocarcinoma. The aim of this study was to evaluate the possible correlation between the HER-2 status and the ABO blood group. HER-2 status determination and routine ABO typing was performed according to current standards. We evaluated the correlation between the HER-2 status and the ABO and Rhesus ( $\mathrm{Rh}$ ) system in 100 consecutive patients with adenocarcinoma of the upper gastrointestinal tract. There were no significant differences between HER-2 status and ABO and $\mathrm{Rh}$ system. Furthermore, no correlation was observed between the HER-2 status and the ABO and Rh type in patients with adenocarcinoma of the upper gastrointestinal tract.
\end{abstract}

\section{Introduction}

The ABO blood group system was initially described by Landsteiner (1), resulting in the Nobel Prize in 1930, following its worldwide introduction for the standardized definition of blood types in 1928. The ABO blood group is determined by the antigens that are present on the surface of the red blood cell membrane. The ABO blood group system is the most important characteristic in terms of blood transfusions and includes four different main groups: A, B, AB and O. The Rhesus (Rh) system is the second clinically most relevant system in human blood transfusions and is determined by molecules that span the width of the red blood cell membrane. The term $\mathrm{Rh}$ was also coined by Karl Landsteiner in 1937, based on his experiments

Correspondence to: Professor Michael Hejna, Division of Oncology, Department of Internal Medicine I, Comprehensive Cancer Center, Medical University of Vienna, 18-20 Waehringer Guertel, A-1090 Vienna, Austria

E-mail: michael.hejna@meduniwien.ac.at

Key words: blood group, human epidermal growth factor receptor-2 status, gastroesophageal cancer, adenocarcinoma with rhesus monkeys, and comprises the Rh antigens $\mathrm{C}, \mathrm{D}$ and $\mathrm{E}$. Among these three main Rh antigens, the D antigen is the most likely to provoke an immune response.

Based on the encouraging results of the ToGA trial, the assessment of the overexpression of the human epidermal growth factor receptor-2 (HER-2) protein and/or amplification of the HER-2 gene, which seems to possess the best predictive properties, is currently included in the diagnostic procedure for patients with advanced-stage gastroesophageal adenocarcinoma, since the administration of trastuzumab with a platinum/fluoropyrimidine doublet is considered a viable treatment option (2). Only patients exhibiting overexpression of the HER-2 protein, as defined by an immunohistochemistry (IHC) score of 2+ and HER-2 gene amplification with fluorescence in situ hybridization (FISH) or colorimetric in situ hybridization (CISH) and an IHC score of $3+$, are considered to be candidates for treatment with trastuzumab. HER-2 overexpression was reported in $6-35 \%$ of patients with gastroesophageal adenocarcinoma (3-5). The differences in HER-2 expression between those trials may be explained by the differences in methodology and sample size in the respective series.

The first association between the ABO blood group system and cancer risk was reported in gastric cancer (GC) patients in the early 1950s (6). Aird et al (6) reported that blood group $\mathrm{O}$ conferred a protective advantage, whereas blood group A was associated with an increased risk for development of GC. The association between an increased risk of GC and blood group A was also confirmed by a study conducted 60 years later $(7)$.

Those findings prompted us to investigate a possible correlation between the ABO blood group system, including the Rh factor, and the HER-2 status in patients with histologically diagnosed adenocarcinoma of the upper gastrointestinal tract at the Medical University of Vienna.

\section{Materials and methods}

Determination of the HER-2 status. The expression of HER-2 protein was detected by IHC, performed as previously described by Hofmann et al (8), using the monoclonal antibody 4B5 (Ventana Medical Systems, Inc., Tucson, AZ, 
Table I. Blood group and Rh status (total and subgroups).

\begin{tabular}{|c|c|c|c|c|c|c|c|c|}
\hline \multirow[b]{2}{*}{ Variables } & \multicolumn{8}{|c|}{ ABO groups } \\
\hline & $\mathrm{AD}+$ & A D- & $\mathrm{B} \mathrm{D}+$ & B D- & $\mathrm{O} \mathrm{D}+$ & O D- & $\mathrm{AB} D+$ & AB D- \\
\hline Total $(n=100)$ & 33 & 9 & 15 & 2 & 28 & 10 & 3 & - \\
\hline Female & 10 & 3 & 3 & 1 & 9 & 3 & 3 & - \\
\hline Male & 23 & 6 & 12 & 1 & 19 & 7 & - & - \\
\hline \multicolumn{9}{|c|}{ Gastric cancer - diffuse type $(n=23)$} \\
\hline Female & 2 & 1 & - & - & 3 & 2 & 1 & - \\
\hline Male & 6 & - & 1 & - & 6 & 1 & - & - \\
\hline \multicolumn{9}{|c|}{ Gastric cancer - intestinal type $(n=24)$} \\
\hline Female & 3 & - & 2 & 1 & 2 & 1 & - & - \\
\hline Male & 5 & 1 & 4 & 1 & 3 & 1 & - & - \\
\hline \multicolumn{9}{|c|}{ Esophageal cancer $(n=53)$} \\
\hline Female & 5 & 2 & 1 & - & 4 & 1 & 2 & - \\
\hline Male & 12 & 5 & 7 & - & 10 & 4 & - & - \\
\hline
\end{tabular}

Rh, Rhesus.

USA) and a BenchMark ULTRA immunostainer (Ventana Medical Systems, Inc.). In a surgical specimen, staining of $\geq 10 \%$ of the tumor cells is required to yield a moderate to strong complete or basolateral staining, whereas in biopsies, a cluster of a least 5 positive cells is required to determine HER-2 positivity with IHC. A weak to moderate complete or basolateral membranous reactivity in $>10 \%$ of the tumor cells is assigned an IHC score of $2+$ and classified as equivocal. The patterns are scored as IHC $3+$ in cases of moderate to strong complete or basolateral membranous reactivity, confirmed at low magnification (2.5- to 5-fold) in $>30 \%$ of the tumor cells. The amplification status of the HER-2 gene was investigated in all cases with an IHC score of $2+$, using a dual-color CISH (INFORM, Ventana Medical Systems, Inc.) or dual-color FISH assay (Pathway, Abbott Molecular Inc., Des Plaines, IL, USA), according to the manufacturer's instructions. A ratio of $\geq 2$ between HER-2 gene signals and chromosome 17 signals assessed in 20 tumor cells was selected as the cut-off to define gene amplification. All tumors exhibiting either an IHC score of $3+$ for the expression of HER-2 or an IHC score of $2+$ in combination with amplification of the HER-2 gene demonstrated by CISH or FISH, were considered to have a positive HER-2 status.

This study was approved by the ethics committee of Medical University of Vienna (Vienna, Austria).

Determination of blood group. Routine serological ABO and $\mathrm{Rh}$ testing for the determination of the blood group was performed according to current standards (9). For blood group typing and antibody screening, a column agglutination method was used (DiaMed-ID Micro Typing system; DiaMed AG, Cressier, Switzerland).

Statistical analysis. Correlation between the ABO blood group and the HER-2 status was calculated using the Chi-square analysis or Fisher's exact test. $\mathrm{P}<0.05$ was considered to indicate a statistically significant difference.

\section{Results}

Patient characteristics. A total of 100 consecutive patients with adenocarcinoma of the upper gastrointestinal tract who were diagnosed and treated at our institution were included in this retrospective analysis. Adenocarcinoma of the stomach, including adenocarcinomas of the esophagogastric junction (AEG) type III (subcardial GC infiltrating the gastroesophageal junction and distal esophagus from below) according to the Siewert classification, was histologically diagnosed in 46 out of the 100 patients (32 females and 68 males) (10). Esophageal adenocarcinoma (EC) type I and II according to the Siewert classification was diagnosed in the remaining 54 patients.

Blood group. According to the ABO blood group system, the 100 patients were classified as follows: 42 were type A (33 D+ and $9 \mathrm{D}-)$; 17 were type $\mathrm{B}(15 \mathrm{D}+$ and $2 \mathrm{D}-)$; 38 were type $\mathrm{O}(28 \mathrm{D}+$ and $10 \mathrm{D}-)$; and 3 were type $\mathrm{AB}$ (3 D+) (Table I).

HER-2 status. In order to determine the HER-2 status, 24 surgical specimens and 76 endoscopic biopsies were examined and 30 cases $(30 \%)$ were found to be HER-2-positive. There was no difference in HER-2 overexpression between surgical specimens and biopsies. For HER-2 expression rated as $2+$, amplification could only be determined in male patients. In total, $25 \%$ of the female $(n=32)$ and $32 \%$ of the male patients $(n=68)$ were found to be HER-2-positive (Table II). In patients with blood group A D+, HER-2 positivity was detected in 13 patients ( 8 with GC and 5 with EC); in patients with blood group A D-, HER-2 positivity was detected in 2 patients with EC; in patients with blood group B D+, HER-2 positivity 
Table II. Blood group and HER-2 status in gastrointestinal tumors $(\mathrm{n}=100)$.

\begin{tabular}{|c|c|c|c|c|c|c|c|c|}
\hline \multirow[b]{2}{*}{ HER-2 status } & \multicolumn{8}{|c|}{$\mathrm{ABO}$ groups } \\
\hline & A D+ & A D- & B D+ & B D- & $\mathrm{O}$ D+ & O D- & $\mathrm{AB} D+$ & AB D- \\
\hline \multicolumn{9}{|c|}{ HER-2 - $(\mathrm{n}=37)$} \\
\hline Female & 4 & 1 & 1 & - & 7 & 2 & 1 & - \\
\hline Male & 8 & - & 4 & - & 6 & 3 & - & - \\
\hline \multicolumn{9}{|c|}{ HER-2 + $(n=8)$} \\
\hline Female & - & - & - & - & - & - & - & - \\
\hline Male & 2 & 1 & 1 & - & 3 & 1 & - & - \\
\hline \multicolumn{9}{|c|}{ HER-2 ++ [n=34 $\left.\left(9^{\mathrm{a}}\right)\right]$} \\
\hline Female & 3 & 2 & 2 & - & 1 & - & - & - \\
\hline Male & $6\left(3^{\mathrm{a}}\right)$ & $4\left(1^{\mathrm{a}}\right)$ & $5\left(2^{\mathrm{a}}\right)$ & 1 & $7\left(1^{\mathrm{a}}\right)$ & $3\left(2^{\mathrm{a}}\right)$ & - & - \\
\hline \multicolumn{9}{|c|}{ HER-2 +++ $(n=21)$} \\
\hline Female & 3 & - & - & 1 & 1 & 1 & 2 & - \\
\hline Male & 7 & 1 & 2 & - & 3 & - & - & - \\
\hline
\end{tabular}

${ }^{\text {a} H E R-2 ~++~ p l u s ~ a m p l i f i c a t i o n . ~ H E R-2, ~ h u m a n ~ e p i d e r m a l ~ g r o w t h ~ f a c t o r ~ r e c e p t o r-2 . ~}$

Table III. HER-2 positivity according to blood group and type of upper gastrointestinal cancer.

\begin{tabular}{|c|c|c|c|c|c|c|c|c|}
\hline \multirow[b]{2}{*}{ Type of cancer (no. of HER-2 cases) } & \multicolumn{8}{|c|}{$\mathrm{ABO}$ groups } \\
\hline & $\mathrm{AD}+$ & A D- & B D+ & B D- & $\mathrm{O} D+$ & O D- & $\mathrm{AB} D+$ & AB D- \\
\hline \multicolumn{9}{|c|}{ Gastric cancer - diffuse type ( $n=4$ out of 23 ) } \\
\hline Female & - & - & - & - & - & - & 1 & - \\
\hline Male & 3 & - & - & - & - & - & - & - \\
\hline \multicolumn{9}{|c|}{ Gastric cancer - intestinal type ( $n=11$ out of 24$)$} \\
\hline Female & 2 & - & - & 1 & - & 1 & - & - \\
\hline Male & 3 & - & 2 & - & 1 & 1 & - & - \\
\hline \multicolumn{9}{|l|}{ Esophageal cancer ( $\mathrm{n}=15$ out of 53 ) } \\
\hline Female & 1 & - & - & - & 1 & - & 1 & - \\
\hline Male & 4 & 2 & 2 & - & 3 & 1 & - & - \\
\hline
\end{tabular}

HER-2, human epidermal growth factor receptor-2.

was detected in 4 (2 with GC and 2 with EC); in patients with blood group B D-, HER-2 positivity was detected in 1 patient with GC; in patients with blood group O D+, HER-2 positivity was detected in 5 ( 1 with GC and 4 with EC); in patients with blood group O D-, HER-2 positivity was detected in 3 (2 with GC and 1 with EC); and in patients with blood group AB D+, HER-2 positivity was detected in 2 cases ( 1 with GC and 1 with EC) (Table III). The HER-2 status was not associated with the blood group ( $\mathrm{P}=0.113$, Chi-square test $)$ or the $\mathrm{Rh}$ type $(\mathrm{P}=0.113$, Fisher's exact test $)$.

For GC, HER-2 positivity was detected in 15 patients ( 5 females and 10 males) out of the 47 patients (32\%) (Table III). As there are two distinct types of GC, intestinal (well-differentiated) and diffuse (undifferentiated), with distinct epidemiology, morphological characteristics and pathogenesis (11), a subgroup analysis was performed. No overall difference in HER-2 status was observed between diffuse and intestinal types. Subgroup analysis for the diffuse $(n=23)$ and the intestinal type $(n=24)$ revealed HER-2 positivity in 3 patients (male) and in 5 patients ( 2 female and 3 male), respectively, with blood group A D+. For the intestinal type, HER-2 positivity was identified in 2 males with blood group B D+, 1 female with B D-, 1 male with O D+ and 1 female and 1 male with O D-. There was 1 female patient with blood group AB D+ in the diffuse type cohort with HER-2 overexpression (Table III). Primary tumor location (EC vs. GC; $\mathrm{P}=0.869$, Chi-square test) and GC subtype (diffuse vs. intestinal; $\mathrm{P}=0.056$, Chi-square test) were not associated with the ABO blood group. In addition, no significant association was observed between the primary tumor location ( $\mathrm{EC}$ vs. $\mathrm{GC} ; \mathrm{P}=0.47$, Fisher's exact test) or the GC subtype (diffuse vs. intestinal; $\mathrm{P}=0.52$, Chi-square test) with the D- type. 
For EC, HER-2 positivity was detected in 15 (28\%) of the 53 patients ( 3 females and 12 males) (Table III).

\section{Discussion}

Previous studies have suggested the oncological impact of blood groups according to the ABO system. This was initially demonstrated by the association between the risk of GC development and blood group A $(6,7)$, whereas in non-small-cell lung cancer, blood group A is apparently associated with improved survival (12). In addition, an increased risk for ovarian cancer was previously reported in individuals with blood group B (13) and loss of A and B antigens has been associated with an increased metastatic spread in oral cancer (14). Compared with patients with blood group O, those with blood group $\mathrm{A}, \mathrm{AB}$, or $\mathrm{B}$ are considered to be more likely to develop pancreatic cancer $(15,16)$. No association was observed between gastrointestinal stromal tumors and the $\mathrm{ABO}$ blood group system (17).

Data published on the role of the ABO blood group system in breast cancer patients have been inconclusive, which may be attributed to methodological biases. Although certain studies concluded that the ABO blood group system distribution in breast cancer patients was not significantly different from that of the control cohort (18-21), other studies reported either an increased risk of developing breast cancer in patients with blood group A (22) or statistically significant differences between breast cancer patients and controls with respect to blood group A vs. non- $\mathrm{A}(\mathrm{P}=0.019)$ and marginal significance $(\mathrm{P}=0.051)$ for blood group $\mathrm{O}$ vs. non-O (23). No correlation was observed between the HER-2 status and the $\mathrm{ABO}$ blood group and $\mathrm{Rh}$ system in breast cancer patients in two additional studies $(24,25)$.

It was recently reported that the $8,219,743$ individuals living in Austria exhibit a distribution of ABO blood types (without considering D) as follows: blood group A $44 \%$, B 14\%, O 36\% and AB 6\%, respectively (26). In terms of Rh typing, the Austrian population is classified as follows: blood group A D+, 37\%; group A D-, 7\%; B D+, 12\%; B D-, 2\%; $\mathrm{O} \mathrm{D}+, 30 \%$; O D-, 6\%; AB D+, 5\%; and AB D-, 1\% (26). Notably, a comparable distribution was observed in our consecutive 100 cases, i.e., blood group A D+, 33\%; A D-, 9\%; B D+, $15 \%$; B D-, 2\%; O D+, 28\%; O D-, 10\%; AB D+, 3\%; and $\mathrm{AB} \mathrm{D}-, 0 \%$ (Table I). This is inconsistent with previous studies $(6,7)$ that suggested a predominance of blood group A among patients with GC, which contributed $47 \%$ to our cohort. In total, 18 of the 47 (38\%) patients with GC and 24 of the 53 patients (45\%) with EC had blood group A.

An HER-2 overexpression was observed in $30 \%$ of the patients in our study and is in accordance with previously reported results $(3,4)$, ranging from 6 to $35 \%$ of patients with gastroesophageal adenocarcinoma (Table II). For GC, HER-2 positivity was detected in 15 (32\%) of the 47 patients. Notably, HER-2 overexpression was lower in the diffuse type (4/23) when compared to the intestinal type GC (11/24); however, this difference was not statistically significant. For EC, HER-2 positivity was observed in 15 (28\%) of the 53 patients (Table III).

On the basis of the percentage distribution in the individual ABO blood groups, the majority of cases with HER-2 overexpression were encountered among the more frequently represented blood groups, such as, A and O (Table III). Due to our limited sample of gastroesophageal cancer patients, an association between blood group subtypes and HER-2 status was not identified. However, further studies, including larger patient samples are required to determine the role of the $\mathrm{ABO}$ blood group system in patients with adenocarcinoma of the upper gastrointestinal tract and its asociation with the HER-2 status.

\section{References}

1. Landsteiner K: Zur Kenntnis der antifermentativen, lytischen und agglutinierenden Wirkungen des Blutserums und der Lymphe. Zentralbl Bakteriol 27: 357-362, 1900 (In German).

2. Bang YJ, Van Cutsem E, Feyereislova A, et al; ToGA Trial Investigators: Trastuzumab in combination with chemotherapy versus chemotherapy alone for treatment of HER2-positive advanced gastric or gastro-oesophageal junction cancer (ToGA): a phase 3, open-label, randomized controlled trial. Lancet 376: 687-697, 2010

3. Bang Y, Chung H, Sawaki A, Xu J, Shen L, Lipatov O, Park SR, Gangadharan VP, Advani SH and Kang YK: HER-2-positivity rates in advanced gastric cancer (GC): Results from a large international phase III trial. J Clin Oncol 26 (Suppl): 4526, 2008

4. Bang Y, Chung H, Xu J, Lordick F, Sawaki A, Al-Sakaff N, Lipatov O, See C, Rueschoff J and Van Cutsem E: Pathological features of advanced gastric cancer (GC): Relationship to human epidermal growth factor receptor 2 (HER2) positivity in the global screening programme of the ToGA trial. J Clin Oncol 27 (Suppl): 4556, 2009.

5. Schoppmann SF, Jesch B, Friedrich J, Wrba F, Schultheis A, Pluschnig U, Maresch J, Zacherl J, Hejna M and Birner P: Expression of Her-2 in carcinomas of the esophagus. Am J Surg Pathol 34: 1868-1873, 2010.

6. Aird I, Bentall HH and Roberts JA: A relationship between cancer of stomach and the ABO blood groups. Br Med J 1: 799-801, 1953.

7. Edgren G, Hjalgrim H, Rostgaard K, Norda R, Wikman A, Melbye $M$ and Nyren O: Risk of gastric cancer and peptic ulcers in relation to ABO blood type: a cohort study. Am J Epidemiol 172: 1280-1285, 2010.

8. Hofmann M, Stoss O, Shi D, Buttner R, van de Vijver M, Kim W, Ochiai A, Ruschoff J and Henkel T: Assessment of a HER2 scoring system for gastric cancer: results from a validation study. Histopathology 52: 797-805, 2008.

9. Fridey J (ed): Standards for Blood Banks and Transfusion Services. 22nd edition. American Association of Blood Banks, Bethesda, MD, 2002.

10. Siewert JR and Stein HJ: Classification of adenocarcinoma of the oesophagogastric junction. Br J Surg 85: 1457-1459, 1998.

11. Lauren P: The two histological main types of gastric carcinoma: Diffuse and so-called intestinal-type carcinoma. An attempt at a histo-clinical classification. Acta Pathol Microbiol Scand 64: 31-49, 1965.

12. Lee JS, Ro JY, Sahin AA, Hong WK, Brown BW, Mountain CF and Hittelman WN: Expression of blood-group antigen A - a favorable prognostic factor in non-small-cell lung cancer. N Engl J Med 324: 1084-1090, 1991.

13. Gates MA, Wolpin BM, Cramer DW, Hankinson SE and Tworoger SS: ABO blood group and incidence of epithelial ovarian cancer. Int J Cancer 128: 482-486, 2011.

14. Dabelsteen E and Gao S: ABO blood-group antigens in oral cancer. J Dent Res 84: 21-28, 2005.

15. Wolpin BM, Chan AT, Hartge P, Chanock SJ, Kraft P, Hunter DJ, Giovannucci EL and Fuchs CS: ABO blood group and the risk of pancreatic cancer. J Natl Cancer Inst 101: 424-431, 2009.

16. Lennon AM, Klein AP and Goggins M: ABO blood group and other genetic variants associated with pancreatic cancer. Genome Med 2: 39, 2010.

17. Ürün Y, Utkan G, Yalcin Ş, et al: Lack of any relationship between $\mathrm{ABO}$ and $\mathrm{Rh}$ blood groups and clinicopathological features in patients with gastrointestinal stromal tumors: Turkish Oncology Group. Asian Pac J Cancer Prev 13: 4129-4131, 2012.

18. Costantini M, Fassio T, Canobbio L, Landucci M, Resasco M and Boccardo F: Role of blood groups as prognostic factors in primary breast cancer. Oncology 47: 308-312, 1990. 
19. Aird I, Bentall HH, Mehigan JA and Roberts JA: The blood groups in relation to peptic ulceration and carcinoma of colon, rectum, breast, and bronchus; an association between the $\mathrm{ABO}$ groups and peptic ulceration. Br Med J 2: 315-321, 1954.

20. Goldenberg IS and Hayes MA: Breast carcinoma and ABO blood groups. Cancer 11: 973-974, 1958.

21. Dede DS, Aksoy S, Dizdar O, Cerci P, Gullo I, Ozisik Y and Altundag K: Blood ABO groups and risk of breast cancer. Med Oncol 27: 1433, 2010.

22. Stamatakos M, Kontzoglou K, Safioleas P, Safioleas C, Manti C and Safioleas M: Breast cancer incidence in Greek women in relation to $\mathrm{ABO}$ blood groups and $\mathrm{Rh}$ factor. Int Semin Surg Oncol 6: 14, 2009.
23. Urun Y, Koru-Sengul T, Altundag K, Utkan G, Onur H, Akbulut H, Demirkazik A and Icli F: ABO blood group and the risk of breast cancer: Multicenter, case-control, observational study. J Clin Oncol 30 (Suppl): 1572, 2012.

24. Ürün Y, Utkan $\mathrm{G}$, Altundag $\mathrm{K}$, et $a$ : $\mathrm{ABO}$ and $\mathrm{Rh}$ blood groups frequency in women with HER2 positive breast cancer. J BUON 17: 457-460, 2012

25. Klimant E, Glurich I, Mukesh B and Onitilo AA: Blood type, hormone receptor status, HER2/neu status, and survival in breast cancer: a retrospective study exploring relationships in a phenotypically well-defined cohort. Clin Med Res 9: 111-118, 2011.

26. Austrian Red Cross: Blood Groups. www.roteskreuz.at. Accessed July 19, 2012 